\title{
O suicídio e sua essência transgressora ${ }^{1}$
}

\author{
Fernanda Cristina Marquetti* \\ Universidade Federal de São Paulo (Unifesp), São Paulo, SP, Brasil
}

Resumo: Este ensaio pretende discutir como o suicídio pode ser concebido por meio de suas características de transgressão do domínio da vida privada e do padrão ocidental de morte. Para demonstrar essa hipótese, nós discutiremos alguns eventos suicidas: fragmentos de cenas de suicídios privados, um suicídio público e um suicídio ocorrido no limite do espaço público-privado. Nossas análises apontam para o suicídio como transgressão em sua essência, no qual abordaremos as reações, de sujeitos e instituições, derivadas desse ato processual de violação de tabus que é o suicídio.

Palavras-chave: suicídio, comunicação, morte, tabu, cultura.

Neste ensaio são abordadas algumas reflexões oriundas da pesquisa etnográfica $O$ suicídio como espetáculo na metrópole de Marquetti (2012). Devido às subjetividades construídas pelos sujeitos na etnografia, alguns conceitos pertinentes à temática do suicídio foram redimensionados a partir da experiência de campo. Ou seja, valores tradicionalmente articulados aos conceitos de morte, suicídio, público-privado, transgressão, tabu, entre outros foram radicalmente reapreciados.

A primeira perspectiva que merece apreciação é a concepção de suicídio como evento de foro íntimo. A princípio considerávamos o suicídio um evento particular, pessoal e que guardava certo afastamento daqueles que cercavam o sujeito suicida. Antes da pesquisa etnográfica, e numa perspectiva limitada a questões psicológicas individuais, foi empreendida uma pesquisa exploratória realizada através de entrevistas com familiares de suicidas. Nessa etapa ocorreu nosso primeiro impacto com o tema. Uma ênfase inesperada às cenas suicidas foi dada por parte dos entrevistados, caracterizando os suicídios como espetáculos, nas quais cenas, espectadores e cenários tomaram uma centralidade na situação descrita pelos familiares. O histórico de vida do suicida e suas características psicológicas revelaram-se secundárias no processo de campo, pois os familiares pouco abordavam o tema e não respondiam nossas questões.

A perplexidade tomou conta desta fase exploratória, pois acreditávamos que o suicídio era algo de foro

1 O ensaio apresentado teve origem na pesquisa de mestrado "O suicídio como espetáculo na metrópole de São Paulo: cenas, cenários e espectadores", realizada na Faculdade de Saúde Pública/USP e teve apoio do Conselho Nacional de Desenvolvimento Científico e Tecnológico. Posteriormente, esta pesquisa foi publicada em formato de livro em 2012. Agradecimentos à Flávia Regina Marquetti pela assessoria e revisão de texto.

* Autor correspondente: femarquetti@uol.com.br íntimo e um evento que se fechava em si mesmo. Ao buscar uma resposta no histórico do suicida através de uma autópsia psicológica encontramos outras proposições-respostas dos familiares que apontavam para as relações externas do suicida com seu mundo. Essas relações estavam articuladas através de seus objetos de cena, seus lugares eleitos para a morte, a composição de cenários, a eleição de espectadores, enfim, a produção imagética do evento suicida, envolvendo horários e dias de eleição para a morte, verdadeiros scripts, plateias eleitas para visualizar as cenas, entre outros elementos. Tudo isto apontava uma perspectiva de estudo muito diversa da habitual dentro desta temática.

A partir disso a hipótese central da pesquisa etnográfica estava definida: o suicídio como espetáculo com cenas, espectadores e cenários. Esta hipótese foi ampliada com outras questões, pois, se o suicídio é um espetáculo, ele também é uma forma de comunicação, e esta comunicação imagética envolve estetização, mensagens, cenários construídos ou utilizados e, os receptores dessa forma de comunicação, os espectadores.

Também foi observado durante o processo que, como pano de fundo desses espetáculos suicidas, havia outras formas de morte na sociedade moderna. No padrão de morte ocidental abordado por Ariès (1989) temos o evento da morte como algo discreto, privado, íntimo, hospitalar, higienizado e controlado tecnicamente. E o suicídio, à medida que se mostrava como forma de comunicação, apontava para outra direção, contrariando o estilo de morte ocidental e estabelecendo um diálogo com outras formas de morte da sociedade atual.

Por outro lado, se os suicídios tornavam-se uma forma de comunicação, eles transitavam da vida privada (íntima) para a vida pública (família e/ou sociedade). Concluí-se que a intersubjetividade estabelecida entre o suicida e seu espectador (presente ou póstumo) apontava para as controvérsias entre o público-privado da sociedade moderna e, também, para as discussões acerca do padrão de morte na cultura ocidental. Este percurso inicial de pesquisa nos 
retirou das perspectivas teóricas do suicídio centradas nas abordagens e técnicas da saúde, da psicologia, da epidemiologia e nos lançou em uma arena incomum. Ou seja, foi articulada uma discussão de como o suicídio se coloca como forma de transgressão às regras do público-privado e às rígidas prescrições do lugar da morte na sociedade atual. Neste viés apontamos que o evento suicida é transgressor em sua essência.

O desenho da etnografia se delineou numa abordagem do suicídio através da tríade: cena, espectador e cenário. Na pesquisa de campo buscamos os óbitos por suicídio através de dados do Programa de Aprimoramento de Informação de Mortalidade do Município de São Paulo (PRO-AIM) e recuperamos a cena suicida por meio da descrição dos espectadores, sendo o cenário fotografado e descrito a partir da indicação do atestado de óbito (o local de ocorrência) e dos espectadores; além disso, estes foram entrevistados como interlocutores e receptores da mensagem do espetáculo suicida. Neste trabalho de pesquisa etnográfica optamos por abordar os "suicídios públicos", ou seja, aqueles que ocorreram em vias públicas da cidade. Desta forma alcançamos a característica de suicídio-espetáculo para a cidade, embora, acreditemos que todos os suicídios guardam esta característica de comunicação, mesmo quando ocorrem em espaços privados.

Sendo assim, neste ensaio vamos destacar a relação existente entre estes dois tipos de suicídio com o universo público-privado: os suicídios públicos, que ocorrem nos interstícios da cidade; e os privados ocorridos nos interstícios das residências. Apresentamos casos de suicídios públicos e privados, aqueles se reportam à etnografia citada e estes dizem respeito à pesquisa exploratória da época.

\section{Da subversão das regras}

O suicídio, imerso nos comportamentos padrões de nossa cultura, aparentemente subverte muitas regras. Sinalizaremos brevemente alguns pontos das relações do público-privado nas sociedades contemporâneas para introduzir essa questão. Sennett (1995) discutiu estes aspectos e revela um fenômeno que denominou de vírus da intimidade. A tirania da intimidade manifesta-se em vários sintomas: promoção exclusiva de relações sociais fundadas na personalidade, uma psicologização da vida social, valorização excessiva das relações privadas em detrimento das relações público/sociais e outras. Essa idolatria da intimidade e degradação da vida e espaços públicos, a que o autor se refere, está presente na sociedade contemporânea, consequentemente, nas práticas da morte. Observamos um recolhimento de todas as práticas sociais, afetivas, cotidianas, de consumo, em direção aos espaços da vida privada. Dessa maneira, esse novo estilo de vida com a subtração do espaço público acarreta aos sujeitos inúmeras consequências.

A interiorização da vida em todos os sentidos subtraiu do espaço externo/público a possibilidade deste ser um lugar onde ocorrem as práticas significativas espirituais, anímicas, religiosas e de existência humana. $\mathrm{Ou}$, pelo menos, indicou que o local adequado para os sentimentos, para as experiências íntimas, comemorações, sociabilidade, a vida enfim, era dentro de lugares privados, na intimidade das residências e similares. Neste mesmo processo de interiorização da vida observamos que a morte, também, foi direcionada para os espaços privados e delimitada a lugares restritos e específicos na vida urbana. No caso da morte, coube a ela o espaço hospitalar, segundo Ariès (1989). Entretanto, vemos os suicídios públicos contrariando essa regra, ao trazer a morte para o espaço público, e, desta forma, subvertendo a construção dos espaços e das sociabilidades que transitam no par público-privado.

No esvaziamento do espaço público observado nas sociedades modernas, o suicídio público pode ser colocado como um contraponto desta tendência. Nestes locais que se tornaram esvaziados dos aspectos urbano e social, os casos de suicídios públicos ocupam um lugar importante, pois, concreta e simbolicamente, transformam estes espaços. Na sociedade atual a população citadina parece recuperar/reinventar o espaço público de forma diferente, seja através do lazer, da violência, da arte e até mesmo da morte. Porém, nesse processo de transgressão que o suicídio público cria, encontramos formas de reação que o "empurram" de volta para o espaço privado. Deparamo-nos com algumas dessas situações durante a pesquisa que destacaremos adiante.

Os suicídios privados (aqueles que ocorrem em espaços particulares, reservados e protegidos) também demonstram seu caráter de transgressão às regras do público-privado, se elas não ocorrem em função da localização no espaço geográfico, dão-se em função das práticas afetivas. Estes suicídios transigem quanto à adequação do lugar, mas rompem com a prática de discrição imposta aos afetos na vida contemporânea. Estes eventos são marcados por uma exibição, dita exacerbada, de paixões e emoções. Ousar trazer a morte, com seus sentimentos, mensagens, cenas para o lugar do habitat cotidiano e familiar contraria as regras de estabilidade do público-privado. Entretanto, neste caso é o afeto provocado que é publico em demasia. Embora, o local adequado para os sentimentos e as experiências íntimas seja o espaço privado das residências, a morte com sua falta de racionalidade e suas emoções exigem, por parte da sociedade, um lugar mais sigiloso, mais asséptico e racional: o hospital.

Os eventos de suicídios talvez sejam uma das poucas situações nas quais é possível uma experiência com a morte na sociedade contemporânea, para além dos rituais de afastamento programados na cultura. Nestes rituais que envolvem um número de aparatos diversos, como velórios em lugares externos às residências, maquiadores profissionais, preparadores do "corpo", crematórios, enterramento organizado por especialistas, e, principalmente, a morte no hospital; raras vezes a muralha em torno da morte pode ser transposta. Enfim, o fenômeno da morte tornou-se discreto e afastado dos olhos dos vivos, mas o suicídio não.

Dessa forma temos, com o suicídio, uma transgressão da morte interdita. Essa questão se colocou em nosso 
trabalho, na medida em que o suicídio mostrou que expõe relações peculiares com o padrão de morte vigente. A morte tem sido tratada diferentemente em várias épocas e a sua atual conformação parece intrinsecamente relacionada à subjetividade da vida moderna. Concomitante ao processo de esvaziamento do espaço público e retração do homem para o domínio do privado, observou-se no contemporâneo uma interdição da morte e de seus derivativos. Isto é, a morte foi escamoteada e reservada aos espaços específicos, seus sinais suprimidos, sendo, cada vez mais um fenômeno silenciado.

Ariès (1989) faz um relato da trajetória de como a morte foi tratada em diferentes épocas. Este autor discute as insidiosas e lentas modificações ocorridas no ato da morte, nos cemitérios, testamentos, nas sepulturas, no luto, nos rituais de morte, nas emoções, enfim, em todos os aspectos entorno da morte.

Desta forma, articulamos nossas reflexões com pontos relevantes das transformações no processo cultural da morte e com o progressivo "enclausuramento" da vida pública, e, concomitantemente, com o seu avesso, o suicídio privado ou público. Segundo Marquetti (2013):

O suicídio, sob esta ótica, deixa de ser algo incompreensível, anormal para mostrar uma articulação extremada de conflito que não encontra outra resolução exceto a morte. ... Podemos pensar o suicídio como um evento que se produz dentro de um conflito social maior e que pressiona as formas culturais usuais referentes ao padrão de morte ocidental, produzindo, assim, uma forma de morte diferente dos padrões ocidentais de discrição, silêncio, higiene, medicalização, etc. O suicídio-espetáculo pode ser um evento que descobre uma das fissuras na sociedade contemporânea e que permite trazer à tona um padrão cultural diverso, trazendo a morte para o meio social e elaborando-a de forma diferente, contrariando a padronização cultural da morte no ocidente. (p. 27)

\section{Suicídios privados}

Ao buscar em papéis guardados os primeiros casos de suicídio privado pesquisados em 1992 que desencadearam a pesquisa etnográfica sobre suicídio e este ensaio, nos reencontramos com as primeiras situações que fazem refletir na possibilidade do suicídio como espetáculo.

Relembramos as situações de campo, os dias de pesquisa em lugares distantes da periferia da cidade, da insegurança ao buscar esses eventos, das visitas às famílias e, também, ao se deparar com colocações de outros pesquisadores sobre o tema que atestavam que esta hipótese era ousada, absurda e improvável. Mesmo assim, apesar das dificuldades da primeira pesquisa, das negativas recebidas de pesquisadores, das angústias em depurar as ideias, era tão genuína a perspectiva que emergia de famílias perdidas diante da falta de sentido de um suicídio, que a hipótese se impôs como uma ferramenta de articulação teóricometodológica. Creditamos a essas famílias entrevistadas o mérito da hipótese construída na pesquisa, pois elas formularam a proposta, sendo a contribuição desta pesquisadora apenas a escuta atenta.

Passados 21 anos de estudos nesta temática, haveria outros casos de suicídio privados que poderiam ser buscados, mas eram emblemáticos para essa descoberta. Diante de dados esparsos, associações frágeis com inúmeras variáveis, os "dados mornos" sobre os suicídios, como já mencionava Durkheim (2008), silenciosamente, surgiram as cenas dos suicidas com seus espetáculos. Naquele momento esta hipótese era nebulosa, mas hoje nos parece um fato bem evidente.

Os casos iniciais dos quais surgiu a ideia de suicídio espetáculo foram recortados de fragmentos do diário de campo (entrevistas e observações de campo) consultado. Pode-se observá-los de forma literal, conforme descritos na época ${ }^{2}$, a seguir:

Fragmento 1: Cleide, solteira, 24 anos, empregada doméstica, morava com dois irmãos num conjunto de barracos feitos com pedaços de madeira e papelão e localizados no declive de uma vala de esgoto. Este conjunto está situado entre duas ruas bem próximas onde existem casas de classe média e classe alta, comércio, praças, etc. Há, portanto, um contraste socioeconômico visível entre moradores deste local. Conforme relato da irmã de Cleide, o suicídio se deu na casa da patroa de Cleide, onde ela trabalhava há três dias. Durante o período de trabalho ela pegou a arma do patrão e deu um primeiro tiro na parede e outro na sua cabeça. Durante a entrevista surgiram dados sobre Cleide que mostram que seu ato não foi tão insólito quanto aparentava. Cleide tinha aspirações, terminou o primeiro grau, fez curso de datilografia e costura e seu último emprego foi em um banco. Sua irmã diz que ela era revoltada, que sofreu muito na infância, era filha adotiva e os pais adotivos faleceram. Cleide se mata dias após sofrer uma queda social, pois perdeu o emprego no banco e passou a ser doméstica, e escolhe como cenário e instrumento os pertences do patrão a ela inacessíveis e sempre visualizados. A revolta relatada pela irmã fica esclarecida num ato agressivo que suja aquilo que foi ela limpar.

Fragmento 2: Marcelo, 35, eletricista, separado e pai de uma filha. A entrevista foi dada por sua mãe que relata o dia do suicídio. Neste dia Marcelo saiu de casa muito mais cedo para o trabalho, quase escondido. Marcelo foi até o prédio da sua empresa (Eletropaulo), subiu até o quinto andar, retirou suas roupas, o relógio, os documentos de identidade, e despido atirou-se em direção à frente do hall de entrada do prédio. Quando os colegas da empresa começaram a chegar encontraram-no morto em frente ao prédio.

Fragmento 3: Iracema, 25 anos, dona de casa, morava com o marido e suas filhas, ela gostava de morar onde

2 Material de diário de campo, sendo que os nomes utilizados nestes fragmentos são ficcionais a fim de preservar a identidade dos sujeitos envolvidos. 
estava e o marido era bom com ela. A entrevista foi dada por sua sogra. Ela se suicidou em casa, enforcando-se com o cordão do roupão no lustre da sala, em um domingo pela manhã, enquanto as filhas dormiam e o marido fazia feira. Ela foi encontrada pela filha de oito anos. Ninguém soube explicar os motivos de seu suicídio, mas havia referências que ela era nervosa e fazia tratamento.

Colocamos algumas reflexões sobre os eventos suicidas em espaço privado. Estes fragmentos de casos de suicídio, dentre outros, apontaram a perspectiva do evento suicida se configurar como uma mensagem através de suas cenas. Dentro de um universo repleto de questões individuais, psicológicas ou sociais, geralmente, esparsas e sem conexões evidentes com $o$ ato, se destacaram as cenas suicidas como uma possibilidade de compreensão do evento. A ênfase na descrição das cenas durante as entrevistas dos familiares também contribuiu para a percepção que estes elementos eram significativos no contexto. Abordaremos alguns pontos desses casos para discutir a dimensão de comunicação-espetáculo dos suicídios privados (aqueles que ocorreram em espaços íntimos/reservados) e seu caráter de transgressão com o padrão de morte e regras do público -privado na sociedade atual.

O caso de Cleide expõe elementos significativos para a compreensão da dimensão de espetáculo do suicídio, os instrumentos usados na cena suicida (revólver do patrão) e o cenário (residência do patrão que ao mesmo tempo é seu local de trabalho) são todos do universo que ela deseja atingir, seja, pelo seu desejo de ascensão social, ou pela agressividade provinda da limitação imposta aos seus desejos. Esta cena mostra-se como uma forma de expressão de seus conflitos pessoais e sociais. O dia do suicídio é simbólico deste protesto - logo após suas expectativas serem frustradas.

A oposição entre a limpeza, para a qual foi contratada, e a sujeira, que promove na cena, sob a condição de sua própria morte, revelam a dimensão trágica de sua mensagem. As regras de discrição e higiene do padrão de morte da sociedade atual são abruptamente rompidas num ato escandaloso e sujo, bem como as regras de conveniência do público-privado são duplamente rescindidas, pois o suicídio trouxe uma exibição excessiva de afetos ao cotidiano através da agressividade de seu ato.

Como vimos anteriormente, trazer a morte/suicídio e seus sentimentos para o lugar do habitat familiar contraria as regras de estabilidade do público-privado, e, concomitantemente, o lugar onde ocorre o suicídio, apesar de ser privado/residencial, não era o seu lugar de privacidade. Seu espaço de privacidade era na vala de esgoto da favela onde residia.

No evento de Marcelo as características de espetáculo do suicídio são muito enfáticas, pois ele direciona sua cena para uma plateia de espectadores selecionada, ou seja, seus colegas de trabalho. Cena e cenário se completam numa mensagem dirigida ao ambiente de trabalho. A mensagem é clara, pois ele se despe do que possuiu durante a vida, inclusive sua identidade, evidenciando, assim, sua renuncia aos papéis assumidos ou impostos pelo grupo na vida cotidiana, rompendo com todos os elos sociais e afetivos. Apesar de não se ter acesso às informações de suas relações de trabalho, o evidente alvo desta cena suicida não deixa dúvidas sobre a comunicação do suicida.

A morte brutal, pública e visível contraria todos os preceitos do padrão de morte ocidental e, também, as relações entre público-privado são profundamente interrogadas em seu ato suicida. Em primeiro plano temos uma questão de cenário, pois o evento suicida se inicia no espaço privado (no edifício) e termina no espaço público (na rua). Desta forma, o suicida transita do privado para o público com sua morte. A outra ambiguidade do ato suicida está no contexto: o lugar de trabalho é espaço público ou privado? Nas duas perspectivas o suicida aponta com seu ato para as nuances entre público e privado da sociedade moderna. Podemos refletir que ele se suicida no limite desses territórios. Ao fazer de seu suicídio um ato que interroga a dimensão e os limites que conformam público-privado Marcelo deixou colegas de trabalho e familiares atônitos.

No suicídio de Iracema a cena e suas características de dia/hora/local foram verdadeiros adjetivos da mensagem. A sogra dela relatou o episódio com espanto e não conseguia elaborar explicações para sua forma de morte, inclusive reforçava em sua fala a satisfação de Iracema com a vida em família. Entretanto, a cena suicida apontou outra perspectiva.

O evento suicida combina elementos que direcionam a cena para a família, ou seja, o lustre da sala em sua casa e o domingo pela manhã, mostrando o desejo de que seus espectadores póstumos fossem marido e filhas. Esta cena revela dúvidas sobre sua satisfação com a vida familiar-privada. O caráter de transgressão de seu suicídio torna-se evidente, pois ela rompe com o imaginário de lar (território fundamental do espaço privado) trazendo um excesso proibitivo de afetos para este contexto. $\mathrm{O}$ uso do lustre, na sala de visitas, espaço social por excelência, marca a intenção de ruptura da máscara social e familiar a ela atribuída - mãe de família feliz; a escolha do domingo de manhã, dia reservado ao descanso/vida em família, corrobora sua insatisfação com a vida familiar e íntima; fato reforçado pelo uso do cordão do roupão, vestuário destinado ao uso íntimo e não social, além de estar ligado a uma ação higiênica, o banho.

A direção da agressividade da sua cena, como seus alvos, também, revelam um corte radical no padrão de morte, constituindo uma verdadeira ruptura com o desejo contemporâneo de mortes sutis, discretas, delicadas, distanciadas e sem elementos de dramaticidade.

\section{Suicídios públicos}

Eleger um caso para evidenciar a hipótese do suicídio como espetáculo, especialmente os casos de suicídio público, não foi tarefa fácil. Ao rever as narrativas, memórias e imagens das cenas suicidas as possibilidades eram 
inúmeras. Então, nossa escolha se orientou por um dos casos que causou maior perplexidade e que, num primeiro momento, não possibilitava uma explicação. Agora, muito tempo depois, este evento ainda suscita espanto quando das lembranças de seus detalhes. Citando Marquetti (2013):

A cena neste caso foi inusitada. Renata veio pela rua de bicicleta, entrou pela portaria do prédio rapidamente, levando a bicicleta pela mão. Ela foi chamada pelo porteiro, mas não o atendeu e a seguir ela estacionou sua bicicleta próxima ao elevador de serviço. Depois ela pegou o elevador, desceu no oitavo andar, tirou os sapatos, e se atirou do hall deste andar pela janela basculante do prédio. O porteiro acionou a segurança interna do prédio quando Renata não parou na portaria, mas não houve tempo para nada. Ele observou que o elevador parava no oitavo andar e seguindo ouviu o barulho da queda. Depois ele encontrou o corpo já caído nos fundos do prédio. Ninguém a viu se atirando pela janela, apenas presenciaram sua entrada inusitada e intempestiva no prédio. $\mathrm{O}$ porteiro frisou o detalhe dos sapatos que ela retirou ao pular e insistiu numa frase: "Ela mergulhou de lá de cima".

O porteiro relatou que ela entrou com facilidade no prédio porque o portão estava aberto. $\mathrm{O}$ primeiro a encontrar o corpo foi o segurança e a seguir o porteiro. Outras pessoas do prédio também foram ver a cena do suicídio. Segundo o porteiro, Renata não tinha amigos no prédio. E ninguém conseguiu explicar o porquê dela se matar naquele prédio. Ele repetiu várias vezes o relato, explicando os detalhes, como se procurasse uma explicação para o fato. Outra porteira acrescentou que o evento deixou marcas no prédio, e que as empregadas domésticas não querem passar perto do local do suicídio, principalmente, à noite. Diz que ela mesma não gosta nem de olhar o local onde a jovem deixou a bicicleta. Ela disse ainda que a notícia do suicídio no prédio "correu" por toda região até o Largo Treze.

O porteiro, espontaneamente, explicou sobre o sistema atual de segurança do prédio. (Com duas portas, "gaiola" e com sistema de monitoramento, para aquele que se apresenta na portaria esperar até a liberação). Quando perguntei se estas medidas foram tomadas depois do suicídio, ele hesitou, disse que já estavam planejadas. Porém, ficou evidente a correlação que ele próprio estabeleceu entre o suicídio e as medidas de segurança contra intrusos. Ele disse: "É para as pessoas não irem entrando".

O prédio está localizado no final de uma rua, no alto, com uma vista panorâmica e rodeado de prédios aos fundos, direção para a qual Renata se atirou. $\mathrm{Na}$ frente do prédio se observam ruas arborizadas e nos fundos está localizado o cemitério de Santo Amaro. A região é basicamente residencial, de classe média/alta, com praças nas proximidades e quase sem movimentação urbana. A visão do andar de onde ela se jogou, nos fundos, é a das janelas dos outros prédios, que estão voltadas para o local.

A janela basculante de onde ela se atirou tinha uma passagem muito estreita, por onde passa um corpo adulto com dificuldade. Provavelmente, a suicida procurou um lugar calmo para se matar, com poucos espectadores na rua ou prédios vizinhos; porém, com sua estranha entrada em um prédio desconhecido marcou sua cena de forma implacável. (pp. 134-135)

A princípio considerávamos o suicídio como um evento de foro íntimo, conforme já citamos no início deste artigo, provavelmente, esta perspectiva inicial estava influenciada pela nossa cultura ocidental e suas relações com a morte. Durante o processo a perspectiva do evento suicida como fato público foi sendo firmada, mas algumas cenas suicidas embaralhavam as concepções em articulação na pesquisa. $\mathrm{O}$ evento suicida descrito anteriormente foi um deles.

Este caso foi agrupado no subgrupo que denominamos suicídios semipúblicos, nestes, os suicidas apontam um desejo de cena suicida pública, em direção ao externo, mas na construção da cena não ultrapassam alguns limites e, portanto, elaboram uma cena semipública. Marquetti (2013) afirma que estes eventos suicidas foram típicos de suicidas de classe média/alta.

As cenas suicidas que se deram nestes casos apresentaram características de cenas públicas, porém com algumas diferenças fundamentais. As cenas suicidas estavam voltadas para fora do âmbito familiar do suicida, mas ela não se dirigia para o público em geral e sim para um público específico e com perfil sociocultural similar ao do suicida. Analisando aspectos dos suicídios semi-públicos quanto à cena, ao cenário e aos espectadores, encontramos as seguintes características: a cena está voltada para fora, mas é protegida; ela é visível para os outros, mas não para todos. Cenário: é fora da casa, mas não na rua; o espaço é público oficialmente, mas a sociabilidade o define como semipúblico. Espectadores: há uma plateia, mas a plateia é selecionada. (p. 126)

Mas, neste caso, além das características mencionadas anteriormente, houve outras nuances instigantes no evento. Renata, no momento do seu suicídio, transita de seu espaço domiciliar para um espaço externo à sua vida privada.

Entretanto, ela arrasta sua cena suicida para um espaço público no seu referencial, mas privado para aqueles 
que residiam no prédio eleito. Os funcionários e moradores do prédio mostravam-se indignados com a escolha dela e indagavam: "Porque ela fez isto?"

Nos outros casos deste grupo os suicidas se colocavam em cena nos seus prédios e atingiam os espaços intermediários destes locais. Renata ao invadir um espaço privado alheio para encenar seu suicídio marcou duplamente o caráter transgressor do evento. Em primeiro plano, vemos que ela levou a morte para um espaço externo e público, assim, contrariando perspectivas do padrão cultural de morte silenciosa, privada e discreta. Mas, obliquamente, percebemos que ela transgrediu o espaço privado de outros, levando a morte de uma estranha para o domínio privado daqueles sujeitos.

Nesta dupla transgressão, Renata invadiu o espaço privado tão intransigentemente delimitado na nossa cultura e, reiterando sua transgressão, o fez através de uma morte. As reações de repulsa e medidas de proteção que causou no prédio, entre moradores e funcionários, além de evocar a hostilidade em relação à exibição da morte, remetem às reações exacerbadas da nossa cultura quando a intimidade é violada. Desta forma, seu ato suicida duplamente transgressor foi revestido pela indignação desencadeada no enfrentamento dos tabus da morte e da vida privada.

Um último detalhe, que permaneceu em silêncio e sem explicação por algum tempo: porque ela retirou os sapatos num momento tão sôfrego e acelerado como a cena descrita? Talvez, se desvencilhasse do símbolo de contato com o mundo. Como visto em outros casos, ela busca se desvencilhar de um símbolo que marca o contato com o mundo social, os sapatos são um dos itens de vestuário ditos como necessários à boa apresentação diante do grupo, estar descalço em espaço público é um dos indícios de exclusão em nossa sociedade. Dessa forma, os sapatos são uma metonímia do vestuário como um todo e, portanto, da condição civilizada do homem.

\section{Um suicídio no limite entre o público e o privado}

No caso deste suicídio, recebemos a informação no mesmo local em que havia ocorrido, dentro da residência, sendo que nos registros obtidos na fonte primária o caso foi registrado como um óbito por suicídio em via pública. Posteriormente, com a descrição da cena pelos espectadores locais foi possível compreender como e por que o caso foi registrado em via pública. Citando Marquetti (2013):

Ferdinando estava brigando com sua namorada na rua, nas imediações da casa dela. A discussão entre eles aumentou, sua namorada tomou a entrada da casa em frente e ele começou a atirar nela com um revólver. Ela ficou no chão do corredor entre a varanda e a casa, e ele entrou até a sala da casa e se deu um tiro de revólver na cabeça. Assim, a cena que culminou no suicídio começou no espaço público e terminou no espaço privado. Os espectadores neste caso foram os familiares da namorada do suicida, pois todos estavam em casa quando o suicídio aconteceu e também a vizinhança que presenciou o início da cena. O suicida morava algumas ruas abaixo sendo, portanto, conhecido pela vizinhança. Segundo as informantes, familiares da namorada de Ferdinando, ninguém entrou na casa para ver a cena do suicídio. Mas, algumas pessoas se aglomeraram no portão da casa depois da tentativa de homicídio e do suicídio. . . . O cenário do suicídio foi voltado para a sociabilidade local, pois a cena se apresentou para o local onde todos conheciam os envolvidos. (pp. 183-184)

Observamos nesta situação, e em outras da pesquisa, uma rigidez e certa confusão para delimitar o espaço público e o privado pelos técnicos de informação em saúde, quanto aos casos de suicídio. Essas atitudes na distinção entre o público e o privado podem remeter a intolerância construída na sociedade em relação ao lugar adequado da morte/suicídio.

Culturalmente, consideramos que o lugar da morte não deve ser o espaço público, e sim, o espaço privado, preferencialmente, o hospital. Quando um suicídio transita entre o espaço público-privado sua manifestação é percebida como uma desorganização dos padrões da morte e da referência cultural de público-privado. Neste caso temos uma situação em que as manifestações íntimas de relações conjugais, que não são bem aceitas ao espaço público e, menos ainda com uma cena final de suicídio-homicídio, transgrediram duplamente as determinações culturais. A escolha da sala como local de suicídio indica um confronto com o espaço/relações sociais do suicida, acrescido pelo fato de não ser a sua residência, mas sim a da namorada, caracterizando um limite entre o social e o íntimo/afetivo.

Desta forma, neste caso de suicídio privado com cena pública observamos posturas ambíguas e contraditórias, nas quais se desorganizou os critérios técnicos produzidos culturalmente para a morte. O critério adotado para registrar o suicídio em via pública, possivelmente, foi influenciado pela dimensão de público/privado que a sociabilidade produziu.

\section{Considerações finais}

Abordamos o suicídio a partir da hipótese de que este seja um evento transgressor em relação ao padrão de morte ocidental, à medida que contraria preceitos deste padrão como a discrição, o controle técnico, a higiene e a privacidade, conforme aponta Ariès (1998). Observamos também que à morte foi designado um lugar específico: um espaço privado, nomeadamente, o hospital. Desta forma, o suicídio torna-se transgressor em mais um aspecto, ou seja, ele subverte as relações cotidianas em relação às regras do público-privado. Ao retirar-se do lugar a ele designado (o espaço privado e hospitalar) e lançar-se para a vida pública (familiar ou social) o evento suicida contesta dois dogmas 
solidamente erigidos na sociedade ocidental: o tabu da morte e o código de conveniências entre espaço público -privado. Apoiados em Prost e Vincent (2009), discutimos os eventos suicidas enquanto transgressores do padrão de morte ocidental quando infringem as regras de sociabilidade estabelecidas para estes espaços, além dos diferentes matizes que compõem tal transgressão.

Nos casos Cleide e Marcelo foram possíveis estabelecer as relações existentes entre o evento suicida e o ambiente do trabalho. Prost e Vincent (2009) abordam as reorganizações das fronteiras entre público-privado na vida moderna, sobretudo no ambiente de trabalho:

Mas os espaços de convívio não se reorganizam apenas em torno do polo doméstico da vida privada; eles ocupam um lugar protegido dentro da própria esfera pública do trabalho. Aqui o universo é completamente outro, mas as analogias são ainda mais interessantes. De fato, nos locais de trabalho eis que surgem ilhas de sociabilidade informal. (p. 109)

Essas "ilhas de sociabilidade" reportam-se a laços e trocas afetivas no ambiente de trabalho, ou seja, pequenas irrupções neste espaço através de convívios sociais no cotidiano. Entretanto, nos eventos de Cleide e Marcelo, estas ilhas foram criadas a partir da morte. De formas diferentes eles levaram a morte (evento designado como íntimo, particular e privado) para o espaço de sociabilidade do trabalho.

Estes eventos suicidas são transgressores dos códigos de conduta de locais intermediários, o espaço do trabalho. Neste espaço cabem pequenas manifestações pessoais, sutilezas da vida privada que invadem a vida pública do trabalho, mas não comportam um evento tão indiscreto e exacerbado como um suicídio. Segundo as colocações de Prost e Vincent (2009):

A vida privada, expulsa do universo coletivo e público do trabalho, torna a ingressar nele de maneira discreta e tortuosa. Se as fronteiras entre público e privado se tornaram mais nítidas, nem por isso eliminaram contágios mútuos. A separação temporal e espacial da existência em dois âmbitos claramente distintos não só se atenua em suas margens graças a transições complexas, como é também parcialmente superada por um jogo de influências entrecruzadas. (p. 110)

Nas cenas suicidas descritas, não houve discrição ou delineamento sutil de gestos na forma de reinserir a vida privada no espaço público do trabalho. O suicídio rompe abruptamente a fronteira estabelecida entre estes espaços e não há nuances ou transições gradativas. A separação temporal e espacial entre público e privado é rompida à força, num gesto de subversão de regras da sociabilidade cotidiana.
Por outra via, no caso de Iracema, vemos que seu ato suicida dirige-se às transições entre público-privado dentro do próprio território do lar. Pois, mesmo dentro de espaços evidentemente privados como as residências, há locais públicos, privados e fronteiriços e a estes competem diferentes formas de sociabilidade familiar. Seguramente, a sala de jantar e seus adereços são elementos que compõem a vida pública da família. Quando eles são utilizados num evento suicida rompe-se a delicadeza de códigos familiares, referentes às práticas privadas e públicas de um lar, sutilmente construídos no próprio espaço social.

A cena suicida de Renata, em um prédio residencial (mas, que não era seu espaço privado), aponta para as rígidas delimitações entre público-privado de sua classe social média/alta. Ela quebra a rigidez dos limites impostos à sua classe social quando utiliza o lugar privado de outros (e público para ela) para cometer seu suicídio. A descontinuidade entre espaços públicos e privados de determinadas classes sociais específicas é questionada em seu ato. Conforme Prost e Vincent (2009) "A oposição marcada entre uma casa puramente privada e um exterior inteiramente público é uma maneira de apreender o espaço social própria da burguesia" (p. 105).

O espaço desestruturado e esvaziado dos bairros das classes médias, com seus conjuntos habitacionais e prédios, suas relações sociais amorfas e superficiais são revertidos nesta situação. Além disso, o instrumento utilizado, dentro do prédio, para acessar o cenário suicida (o elevador) é digno de destaque na cena, por tratar-se de um lugar geralmente marcado pela neutralidade, polidez, insipidez de relações, e que foi utilizado de forma diversa, pois através dele se dá o percurso da suicida até sua cena final. Sobre este espaço Prost e Vincent (2009) comentam:

As relações com os vizinhos se modificaram. $\mathrm{O}$ elevador não é uma rua na vertical: na rua, a pessoa vê os outros passarem, sabe em que porta vão parar, e a identificação fica mais fácil graças às diferenças entre as casas. $\mathrm{O}$ elevador conduz seus passageiros ao abrigo dos olhares e os entrega em andares totalmente idênticos, e é fácil confundir a entrada dos prédios. A semelhança dos lugares gera o anonimato. (p. 106)

Assistimos, dessa forma, à transformação promovida por Renata no espaço fronteiriço do elevador, pois entre o espaço intermediário do prédio e o lugar privado dos apartamentos, com seu ato suicida, ela remodelou espaços previamente determinados subjetivamente para usos específicos, marcando definitivamente a história do lugar, e redimensionando drasticamente, por meio de seu ato, os locais tidos como público e privado.

O suicídio de Ferdinando, transitando, literalmente, entre o público e privado, se desenrola em uma cena que se inicia na rua, em um bairro tradicional e com relações típicas de sociabilidade de vizinhança, e termina dentro de uma residência. Esta cena aponta para as diferenças entre 
vizinhança, sociabilidades e definições entre público e privado das diferentes classes sociais. Vejamos as colocações de Prost e Vincent (2009):

O bairro antigo ou a vila se apresentam em si mesmos como espaços de transição. O bairro se define subjetivamente, pra seu morador, pelo conjunto de itinerários percorridos a partir de sua casa. Percorridos a pé, naturalmente, pois a área do bairro e a do pedestre, ao passo que o espaço da aglomeração é o do "meio de transporte". O espaço concreto do bairro ou da vila é um espaço aberto a todos, regido por regras coletivas, mas que tem um "foco", no sentido óptico, um lugar fechado, um lar. É um exterior definido a partir de um interior; um público cujo centro é o privado. Esse espaço é o lugar do conhecimento mútuo: cada qual é conhecido num certo número de particularidades da sua vida privada por pessoas que não são parentes, nem amigas, e que, no entanto, não são estranhas - os vizinhos. (p. 100, itálicos nossos)

Ferdinando no script de sua cena suicida apresenta todos os elementos de sociabilidade de um bairro citado, porém, a surpresa reside em tais usos e costumes do bairro ser pronunciado num ato suicida. Vejamos alguns pontos: ele percorre o bairro a pé durante a cena; no espaço aberto a todos ele anuncia $o$ ato final, mas apresenta a cena para a vizinhança; pois este espaço aberto é um lugar fechado, o seu bairro. Prost e Vincent (2009) referem:

O espaço do bairro se distingue do espaço privado, mas não é fechado a ele; pelo contrário, forma a seu redor uma espécie de zona protetora. O convívio permite que o bairro permaneça como um espaço aberto, público, e que, mesmo assim, a vida privada de cada um encontre aí um prolongamento, um eco, um apoio, e às vezes também uma crítica. O bairro ou a vila organizam uma transição complexa entre o público e o privado. (p. 105)

O bairro foi uma zona protetora para Ferdinando encenar seu drama privado e, assim, delinear seu palco entre as ruas do bairro e a residência da namorada, formando uma complexa zona de transição entre público e privado. Prost e Vincent (2009) abordam as nuances na delimitação entre público-privado:

Desse modo, as fronteiras entre público e privado mais se parece desvanecer. Na realidade, ela não desaparece: torna-se apenas mais sutil. Ou melhor, tendo se acentuado a especialização pública ou privada dos espaços e situações, as normas e os códigos sociais em uso nos dois universos se reaproximam. (p. 134)

Por fim, testemunhamos que as cenas suicidas destruíram e reconstruíram os limites entre público e privado, num processo de comunicação de novos sentidos de vida, cotidiano e sociabilidade. As fronteiras entre tais espaços e usos estão em remodelação constante, seria o suicídio uma das formas culturais de indagar, romper e engendrar novas linhas divisórias entre público e privado? Ao que parece, sim.

\section{Suicide and its transgressive essence}

Abstract: This essay aims to discuss how suicide can be conceived through its transgression of the characteristics of the field of privacy and of the western standard of death. To demonstrate this hypothesis, some suicidal events will be discussed: fragments of private suicides scenes, a public suicide and a suicide occurred within the limits of the public-private space. Our analysis points to suicide as transgression in its essence and discuss the reactions of individuals and institutions emerged from this procedural act of violation of taboos.

Keywords: suicide, communication, death, taboo, culture.

\section{Suicide et son essence transgressive}

Résumé: Cet essai a pour objectif discuter sur la façon dont le suicide peut être conçu par ses caractéristiques de transgression du domaine de la vie privée et du paradigme occidental de mort. Pour démontrer cette hypothèse, nous discutons quelques événements suicidaires: fragments de scènes de suicides privés, un suicide public et un suicide survenu dans les limites de l'espace public/privé. Nos analyses pointent vers le suicide comme transgression dans son essence, et nous discutons des réactions des individus et des institutions provenant de cet acte processif de violation de tabous qu'on connait par le suicide.

Mots-clés: suicide, communication, mort, tabou, culture. 


\section{El suicidio y su esencia transgressora}

Resumen: Este trabajo tiene como objetivo discutir cómo el suicidio puede ser concebido a través de sus características transgresoras de la vida privada y del estándar occidental de la muerte. Para demostrar esta hipótesis, se discute algunos eventos suicidas: fragmentos de escenas de suicidios privados, un suicidio público y un suicidio dentro de los límites del espacio públicoprivado. El análisis apunta al suicidio como la transgresión en su esencia, en el cual se discute las reacciones de los individuos y las instituciones, derivadas de este acto de violación procesal del tabú que es el suicidio.

Palabras clave: suicidio, comunicación, muerte, tabu, cultura.

\section{Referências}

Ariès, P. (1989). História da morte no Ocidente (2a ed.). Lisboa, Portugal: Teorema.

Durkheim, E. (2008). O suicídio. São Paulo, SP: Martin Claret.

Marquetti, F. (2013). O suicídio como espetáculo na metrópole. São Paulo, SP: Fap-Unifesp.
Prost, A., \& Vincent, G. (2009). História da vida privada (5th ed.). São Paulo, SP:Companhia das Letras.

Sennett, R. (1995). O declínio do homem público: as tiranias da intimidade (4th ed.). São Paulo, SP: Companhia das Letras.

Recebido: 02/09/2013

Revisado: 14/11/2019

Aceito: 19/02/2014 